\title{
Improving handover between medical rotations for doctors in training - a quality improvement project
}

\author{
Authors: Chaw Kay Khine, ${ }^{\mathrm{A}}$ Brian McCann, ${ }^{\mathrm{A}}$ Jia-Wei Tang ${ }^{\mathrm{A}}$ and Francis Kynaston-Pearson ${ }^{\mathrm{A} *}$
}

\begin{abstract}
Introduction
Handover is an essential part of ward induction for doctors rotating into new medical specialties. There is a lack of formal handover or communication from the previous team, resulting in loss of key knowledge and continuity of care. This hinders new doctors from being effective on the first day and contributes to doctors not feeling adequately prepared before starting in a new rotation. Poor communication is the biggest contributor to hospital errors, ${ }^{1}$ and poor-quality handover jeopardises patient safety. ${ }^{2}$ An up-to-date dedicated handbook or reference guide produced by junior doctors, for junior doctors, has been found to boost doctor confidence, and helped improve their efficiency. ${ }^{3-5}$ We present a pan-trust project aimed at improving handover between doctors during changeover of medical rotations.
\end{abstract}

\section{Methods}

Three pilot sites were identified across both hospital campuses oncology, gastroenterology and rheumatology. A baseline assessment and two further plan, do, study, act (PDSA) cycles were completed in one year period.

\section{PDSA cycle 1 - establish current situation}

We surveyed doctors to evaluate how they rated their current handover (on a scale 0-100) and whether they had received key items of information (with yes/no questions). These data were used to guide the creation of an induction document.

\section{PDSA cycle 2 - refinement}

Survey repeated with the second rotation and compared against baseline. The qualitative feedback was used to further refine the booklets. Short video interviews, entitled 'Doctors Voices', were filmed with outgoing doctors to help pass on 'top tips'.

\section{PDSA cycle 3 - assess usefulness of videos}

A final survey was completed in the third rotation which included additional questions evaluating the impact of the videos.

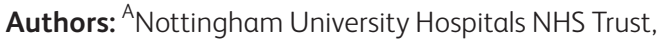
Nottingham, UK; *RCP chief registrar

\begin{tabular}{|c|c|c|c|}
\hline Feedback & Baseline (cycle 1) & Cycle 2 & Cycle 3 \\
\hline $\begin{array}{l}\text { Usefulness of } \\
\text { handover? }\end{array}$ & $57 \%$ & $77 \%$ & $80 \%$ \\
\hline Quality of handover? & $41 \%$ & $72 \%$ & $66 \%$ \\
\hline $\begin{array}{l}\text { How prepared were } \\
\text { you? }\end{array}$ & $48 \%$ & $55 \%$ & $59 \%$ \\
\hline
\end{tabular}

\section{Results}

Responses were received from 28 doctors at baseline, 18 after cycle 2 and 16 after cycle 3.

The usefulness and quality of handover has improved since the introduction of our changes. The induction booklets were very well received gaining 89/100 from survey respondents and the videos having 77/100 (Table 1). Feedback on the induction booklets and videos include:

> 'This is an excellent tool and helped calm my nerves before starting.'

> 'The list of useful numbers and description of a typical day on the ward were really useful.'

> 'The booklet had everything I needed for day one on the job.'

> 'The videos were easier to digest, especially their tips for the job.'

\section{Conclusions}

Those surveyed found the induction booklet and videos useful, and subsequently more prepared to start work. We now intend to:

> roll out the standardised template to all specialties via PGME centre

> embed updating the handover booklet as part of the roles and responsibilities of the ward doctor

> upload the booklets on the intranet and onto NUH guidelines application accessible via smartphone

> create a template for handover to provide clinically relevant information to be transferred between rotations.

\section{Conflicts of interest}

None declared. 


\section{References}

1 Reader T, Flin R, Lauche K and Cuthbertson B. Non-technical skills in intensive care. Brit J Anaesth 2006;96:551-9.

2 Hayes L. Improving junior doctor handover between jobs. BMJ Open Quality 2014;3:u201125.w713.

3 Davies M, Panchal S, Misra N. The handbook: an end to 'I wish I had known that before I started'. BMJ Qual Improv Report 2015;4:u203210.w1579.
4 Ross D, Petrie C, Tully V. Introduction of a junior doctors' handbook: an essential guide for new doctors. BMJ Qual Improv Rep 2016:5:u209167.w3822.

5 Houston J, Barker W, Clarke ] et al. Sharing knowledge, saving time: an online toolbox to aid junior doctors. BMJ Open Quality 2014:2:u200583.w651. 